\title{
Relative hyperglycemia is associated with complications following an acute myocardial infarction: a post-hoc analysis of $\mathrm{HI}-5$ data
}

Tien F. Lee ${ }^{1,2^{*}}$, Morton G. Burt ${ }^{1,2}$, Leonie K. Heilbronn ${ }^{3}$, Arduino A. Mangoni ${ }^{1}$, Vincent W. Wong ${ }^{4}$, Mark McLean ${ }^{4}$ and N. Wah Cheung ${ }^{4}$

\begin{abstract}
Background: Hyperglycemia is associated with increased morbidity and mortality in patients with an acute myocardial infarction (AMI). We evaluated whether complications after AMI are associated with absolute or relative glycemia.

Methods: A total of 192 patients with AMI were randomized to intensive or conventional insulin therapy. Absolute glycemia was defined as mean blood glucose level (BGL) during the first $24 \mathrm{~h}$ following randomization. Relative glycemia was defined by the stress hyperglycaemia ratio (SHR), calculated as mean BGL divided by average glucose concentration over the prior 3 months estimated from glycosylated haemoglobin. The primary endpoint was a "complicated AMI", defined as an AMI complicated by death, congestive cardiac failure, arrhythmia, cardiac arrest, reinfarction, cardiogenic shock, inotrope use or emergency revascularization.

Results: There was not a significant association between mean BGL and complicated AMI (odds ratio (OR) 1.05 per $\mathrm{mmol} / \mathrm{L}$ glucose increment, 95\% confidence intervals (CI) 0.93-1.19). In contrast, SHR was positively associated with a complicated myocardial infarction (OR 1.22 per 0.1 SHR increment, $95 \% \mathrm{Cl} 1.06-1.42$ ), and individual complications of death (OR 1.55, 95\% Cl 1.14-2.11), congestive cardiac failure (OR 1.27, 95\% Cl 1.05-1.54), arrhythmia (OR 1.31, 95\% Cl 1.12-1.54) and cardiogenic shock (OR 1.42, 95\% Cl 1.03-1.97). The relationship between SHR and a complicated AMI was independent of diabetic status, intensive insulin therapy, sex and hypoglycemia.
\end{abstract}

Conclusions: Relative, but not absolute, glycemia during insulin treatment is independently associated with complications after an AMI. Future studies should investigate whether basing therapeutic glycaemic targets on relative glycemia improves patient outcomes.

Keywords: Stress hyperglycemia, Myocardial infarction, Insulin, Cardiac complication

\section{Background}

Hyperglycemia is associated with increased morbidity and mortality in hospitalized patients with a variety of medical conditions [1-3]. However, while the association between glucose concentration in hospital and mortality is strong in patients without known diabetes,

\footnotetext{
*Correspondence: lee0522@flinders.edu.au

${ }^{2}$ Southern Adelaide Diabetes \& Endocrine Services, Repatriation General Hospital, Daw Park, Adelaide, SA 5041, Australia

Full list of author information is available at the end of the article
}

paradoxically glucose concentration is not as strongly associated with mortality in patients with diabetes [2-6]. This suggests that background glycemia influences the relationship between glucose and mortality in patients admitted to hospital.

An elevated blood glucose in a hospitalized patient can occur because a patient has poor chronic glycemic control or if there is an acute increase in glucose, often termed stress hyperglycemia [7]. Stress hyperglycemia is the relative increase in glucose in response to an intercurrent illness. Our group has recently proposed a novel 
metric for relative glycemia termed the stress hyperglycemia ratio (SHR), whereby admission glucose concentration is corrected for background glycemia estimated from glycated hemoglobin $\left(\mathrm{HbA}_{1 \mathrm{c}}\right)$ [8]. We reported that SHR was associated with critical illness in hospitalized patients, independent of absolute glycemia. Moreover, the association between relative glycemia and critical illness was present in patients with and without background hyperglycemia. Since this publication, several other studies have reported that relative glycemia at hospital admission predicts outcomes for patients admitted to hospital with a stroke [9], acute illness [10], acutely ill requiring intensive care unit (ICU) admission [11] and after percutaneous coronary intervention [12]. These studies demonstrate that quantifying relative hyperglycemia at admission to hospital provides important prognostic information in patients with and without diabetes.

Calculation of relative hyperglycemia could also potentially provide a basis for individualized glycemic targets in patients treated with insulin in hospital. If relative hyperglycemia during glucose-lowering treatment was associated with adverse patient outcomes, it would support this hypothesis. However, in our previous study blood glucose levels (BGLs) were not systematically recorded in all patients throughout the hospital admission and this analysis could not be undertaken [8].

The hyperglycemia: intensive insulin infusion in infarction (HI-5) study was a prospective randomized-controlled trial investigating the effect of intensive insulin therapy on mortality in patients with an acute myocardial infarction [13]. In the primary analysis, there was no significant difference in mortality in patients randomized to intensive insulin and conventional care. However, as finger prick BGLs were systematically recorded in both groups, the study cohort provides an opportunity to investigate the association between relative hyperglycemia during glucose-lowering treatment and adverse patient outcomes.

We hypothesized that, in the HI-5 study cohort, relative hyperglycemia during the first $24 \mathrm{~h}$ following AMI would be more strongly associated with an adverse outcomes for patients than absolute glycemia. If true, this would provide supportive evidence for a change in treatment paradigm whereby glucose-lowering treatment in patients following an AMI is targeted at relative, rather than absolute, hyperglycemia. Therefore, the aim of this study was to assess the relationship between relative glycemia and complications following a myocardial infarction and whether this relationship was affected by other potential confounding factors.

\section{Methods}

\section{Study design}

This is a secondary analysis of a prospective randomizedcontrolled trial that has previously been reported [13].
In brief, consecutive consenting patients presenting with an AMI at six hospitals in New South Wales, Australia with either known diabetes or without diabetes and BGL $>7.8 \mathrm{mmol} / \mathrm{L}$ were randomized to receive insulin/ dextrose infusion therapy for at least $24 \mathrm{~h}$ to maintain finger prick BGL between 4 and $10 \mathrm{mmol} / \mathrm{L}$ or conventional therapy comprising their usual glucose-lowering therapy except metformin and supplemental subcutaneous shortacting insulin if finger prick BGL was $\geq 16 \mathrm{mmol} / \mathrm{L}$. BGL were recorded at 8 pre-defined timepoints in all patients $(0700,0900,1200,1400,1700,1900,2200$ and 0300 in all patients). Additional BGLs were performed on an hourly basis in patients on intensive insulin therapy. The study was approved by local ethics committees of Westmead Hospital, Nepean Hospital, Blacktown Hospital, Mt. Druitt Hospital and John Hunter Hospital. All subjects participating in the study provided written informed consent.

\section{Subjects}

This analysis included all participants in the HI-5 study in whom $\mathrm{HbA}_{1 \mathrm{c}}$ was measured at admission to hospital. Patients were treated with angioplasty, thrombolysis or anti-coagulation at the discretion of the admitting doctors. All patients received beta blocker therapy unless specifically contraindicated [13]. Demographic data, laboratory data, and in-hospital mortality and complications that were recorded at the time of the original study were used in the analysis. A Charlson Comorbidity Index was calculated from the co-morbidities recorded during the original data collection [14].

\section{Calculation of stress hyperglycemia ratio}

Finger prick point of care capillary BGLs were measured at predefined time points during the first $24 \mathrm{~h}$ as previously described [13], and the readings were averaged to calculate mean BGL during glucose-lowering treatment for each subject. Estimated average glucose over the prior 3 months was calculated using the equation "estimated average glucose $=\left(1.59 \times \mathrm{HbA}_{1 \mathrm{c}}\right)-2.59$ " derived by Nathan et al. [15] Relative hyperglycemia during glucoselowering treatment (SHR) was then calculated using the formula mean BGL divided by estimated average glucose.

\section{Statistical methods}

Before undertaking this secondary analysis we pre-specified a composite primary endpoint of a "complicated AMI," defined as AMI complicated by death during the hospital admission, congestive cardiac failure, arrhythmia, cardiac arrest, reinfarction, cardiogenic shock, inotrope use or the need for rescue percutaneous transluminal coronary angioplasty (PTCA) or emergency coronary arterial bypass graft (CABG). These events 
were defined as per the original HI-5 study [13]. Reinfarction was defined as a new AMI that occurred at least $72 \mathrm{~h}$ following the index AMI. A patient was considered in congestive cardiac failure if there was documented dyspnea in the notes and the chest X-ray report confirmed pulmonary edema or interstitial edema. Cardiogenic shock referred to a state where the patient was in cardiac failure with a concomitant systolic blood pressure of less than $80 \mathrm{mmHg}$. The primary variables of interest were absolute hyperglycemia, defined as mean BGL during glucose-lowering treatment and relative hyperglycemia, defined as SHR during glucose-lowering treatment.

Characteristics of patients with and without a complicated AMI are reported as mean \pm standard deviation if normally distributed and median (interquartile range) if the distribution was not normal. These variables were compared using unpaired t tests, Mann-Whitney $\mathrm{U}$ tests or Chi squared tests as appropriate. Univariable binomial logistic regression analyses were undertaken to calculate the odds ratio of a complicated AMI for each BGL and SHR increment. Odds ratios for the individual components of the composite primary endpoint for each BGL and SHR increment were also calculated. We then included treatment group and known diabetes and interaction terms for these variables as co-variates in analyses to assess whether they moderated the relationship between SHR and a complicated AMI. Finally, univariable binomial logistic regression analyses were undertaken to examine whether other variables of interest such as sex, age, Charlson Comorbidity Index, hypoglycemia, treatment type and peak creatinine phosphokinase were associated with a complicated AMI. If a variable was not normally distributed, it was log-transformed to achieve a normal distribution before inclusion in regression analyses. Variables that were significantly associated with a complicated AMI in a univariable analysis were then included in a multiple binomial logistic regression analysis.

Statistical analysis was undertaken using SPSS version 23 for Windows (IBM, New York, USA). A two-tailed $\mathrm{p}$ value of $<0.05$ was considered statistically significant.

\section{Results}

\section{Patient characteristics}

A total of 192 subjects were included in the final analysis; 48 patients out of the 240 patients included in the original study cohort were excluded as there were no recorded $\mathrm{HbA}_{1 \mathrm{c}}$. In this cohort, 82 patients were defined as having a complicated AMI: 6 patients died, 22 developed congestive cardiac failure, 48 had an arrhythmia, 21 had a cardiac arrest, 3 had a re-infarction, 5 developed cardiogenic shock, 10 were treated with inotropic support,
26 required a rescue PTCA and 7 an emergency CABG. A number of subjects had more than one complication. Although subjects with a complicated AMI were more likely to be female, there were no significant differences in age, Charlson Comorbidity Index, intensive insulin therapy, known diabetes, other cardiovascular risk factors, cardiovascular medications, serum cholesterol, peak creatinine phosphokinase and use of anticoagulant, thrombolytic and angioplasty treatment and ST elevation on ECG between patients with a complicated and uncomplicated AMI (Table 1).

\section{Associations between absolute and relative glycemia during glucose-lowering treatment and a complicated acute myocardial infarction}

There was not a significant association between mean BGL and the incidence of complicated AMI (odds ratio (OR) 1.05 per $\mathrm{mmol} / \mathrm{L}$ glucose increment, 95\% confidence intervals (CI) 0.93-1.19, $\mathrm{p}=0.437$ ) (Fig. 1a). Furthermore, no individual component of the composite "complicated AMI" endpoint was significantly associated with mean BGL (Fig. 1a). In contrast, SHR was associated with a complicated AMI (OR 1.22 per 0.1 SHR increment, 95\% CI 1.06-1.42, $\mathrm{p}=0.006$ ) (Fig. 1b). Moreover, SHR was positively associated with death (OR 1.55, 95\% CI 1.14-2.11, $\mathrm{p}=0.005)$, congestive cardiac failure (OR 1.27, 95\% CI 1.05-1.54, $\mathrm{p}=0.014$ ), arrhythmia (OR $1.31,95 \%$ CI 1.12-1.54, $\mathrm{p}=0.001$ ) and cardiogenic shock (OR 1.42, 95\% CI 1.03-1.97, $\mathrm{p}=0.033$ ). SHR was not significantly associated with cardiac arrest, reinfarction, inotrope use, rescue angioplasty or emergency CABG (Fig. 1b).

\section{Effect of diabetes and intensive insulin therapy on association between relative glycemia and a complicated acute myocardial infarction}

Figure 2a shows that the relationship between SHR and a complicated AMI was similar in patients with and without diabetes. The association between SHR and a complicated AMI was independent of diabetes status (OR 1.38 per 0.1 SHR increment, 95\% CI 1.08-1.75 $\mathrm{p}=0.009$ ), which was not independently associated with a complicated AMI $(\mathrm{p}=0.204)$. Furthermore there was not a significant interaction between SHR and diabetes status $(\mathrm{p}=0.216)$, demonstrating that diabetes status did not significantly modulate the relationship between SHR and a complicated AMI. Figure $2 b$ shows that the relationship between SHR during insulin treatment and a complicated AMI was not different in patients randomized to intensive insulin and conventional therapy. The association between SHR and a complicated AMI was independent of intensive insulin therapy (odds ratio $=1.37$ per 0.1 SHR increment, $95 \%$ CI 1.09-1.72, 
Table 1 Characteristics of patients with and without a complicated myocardial infarction

\begin{tabular}{|c|c|c|c|}
\hline & Complicated AMI & $\begin{array}{l}\text { Uncomplicated } \\
\text { AMI }\end{array}$ & $p$ value \\
\hline Number & 82 & 110 & \\
\hline Age (years) & $63(10)$ & $61(12)$ & 0.108 \\
\hline Female $[N,(\%)]$ & $24(29)$ & $16(15)$ & 0.017 \\
\hline $\begin{array}{l}\text { Charlson Comorbid- } \\
\text { ity Index }\end{array}$ & $0.5(0.0-1.0)$ & $0.0(0.0-1.0)$ & 0.843 \\
\hline $\begin{array}{l}\text { Intensive insulin } \\
{[N,(\%)]}\end{array}$ & $44(54)$ & $58(53)$ & 0.898 \\
\hline Diabetes [N, (\%)] & $38(46)$ & $53(48)$ & 0.801 \\
\hline \multicolumn{4}{|c|}{ Diagnoses prior to admission } \\
\hline $\begin{array}{l}\text { Hypertension [N, } \\
(\%)]\end{array}$ & $50(61)$ & $57(52)$ & 0.287 \\
\hline $\begin{array}{l}\text { Hyperlipidemia } \\
(\mathrm{N},(\%))\end{array}$ & $44(54)$ & $67(61)$ & 0.388 \\
\hline Smoker [N, (\%)] & $26(32)$ & $35(32)$ & 0.372 \\
\hline $\begin{array}{l}\text { Previous AMI [N, } \\
(\%)]\end{array}$ & $20(24)$ & $21(19)$ & 0.445 \\
\hline \multicolumn{4}{|c|}{ Medications at admission } \\
\hline $\begin{array}{l}\text { ACE inhibitor [N, } \\
(\%)]\end{array}$ & $16(20)$ & $23(21)$ & 0.845 \\
\hline Aspirin [N, (\%)] & $19(23)$ & $28(25)$ & 0.752 \\
\hline $\begin{array}{l}\text { Beta-blocker [N, } \\
(\%)]\end{array}$ & $17(21)$ & $13(12)$ & 0.098 \\
\hline CCB [N, (\%)] & $9(11)$ & $13(12)$ & 0.880 \\
\hline Fibrate [N, (\%)] & $1(<1)$ & $1(<1)$ & 0.826 \\
\hline Nitrate [N, (\%)] & $11(13)$ & $16(15)$ & 0.850 \\
\hline Statin $[\mathrm{N},(\%)]$ & $22(27)$ & $31(28)$ & 0.918 \\
\hline Initial treatment & & & 0.583 \\
\hline $\begin{array}{l}\text { LMWH/heparin [N, } \\
((\%)]\end{array}$ & $22(27)$ & $39(35)$ & \\
\hline $\begin{array}{l}\text { Thrombolysis [N, } \\
(\%)]\end{array}$ & $33(40)$ & $20(18)$ & \\
\hline $\begin{array}{l}\text { Acute PTCA [N, } \\
(\%)]\end{array}$ & $24(29)$ & $49(45)$ & \\
\hline Not documented & $3(4)$ & $2(2)$ & \\
\hline $\begin{array}{l}\text { Total cholesterol } \\
(\mathrm{mmol} / \mathrm{L})\end{array}$ & $4.67(1.31)$ & $4.92(1.23)$ & 0.197 \\
\hline Peak CPK ${ }^{a}$ & $923(292-3130)$ & 1115 (517-2844) & 0.305 \\
\hline STEMI $[N,(\%)]^{b}$ & $62(76 \%)$ & 84 (76\%) & 0.780 \\
\hline
\end{tabular}

$A C E$ angiotensin converting enzyme, $A M I$ acute myocardial infarction, $N$ number of patients with endpoint, $C C B$ calcium channel blocker, $L M W H$ low molecular weight heparin, PTCA percutaneous transluminal coronary angioplasty, Peak CPK peak creatinine phosphokinase, STEMI ST elevation on ECG or presence of Q-waves

Values represent mean (standard deviation) unless otherwise stated; ${ }^{\mathrm{a}}$ Median (interquartile range); ${ }^{\mathrm{b}}$ There were 6 patients missing STEMI status, 2 with uncomplicated AMI and 4 with complicated AMI

$\mathrm{p}=0.006)$, which was not associated with a complicated AMI $(\mathrm{p}=0.173)$. Moreover there was not a significant interaction between SHR and intensive insulin treatment $(\mathrm{p}=0.206)$, demonstrating that treatment group not
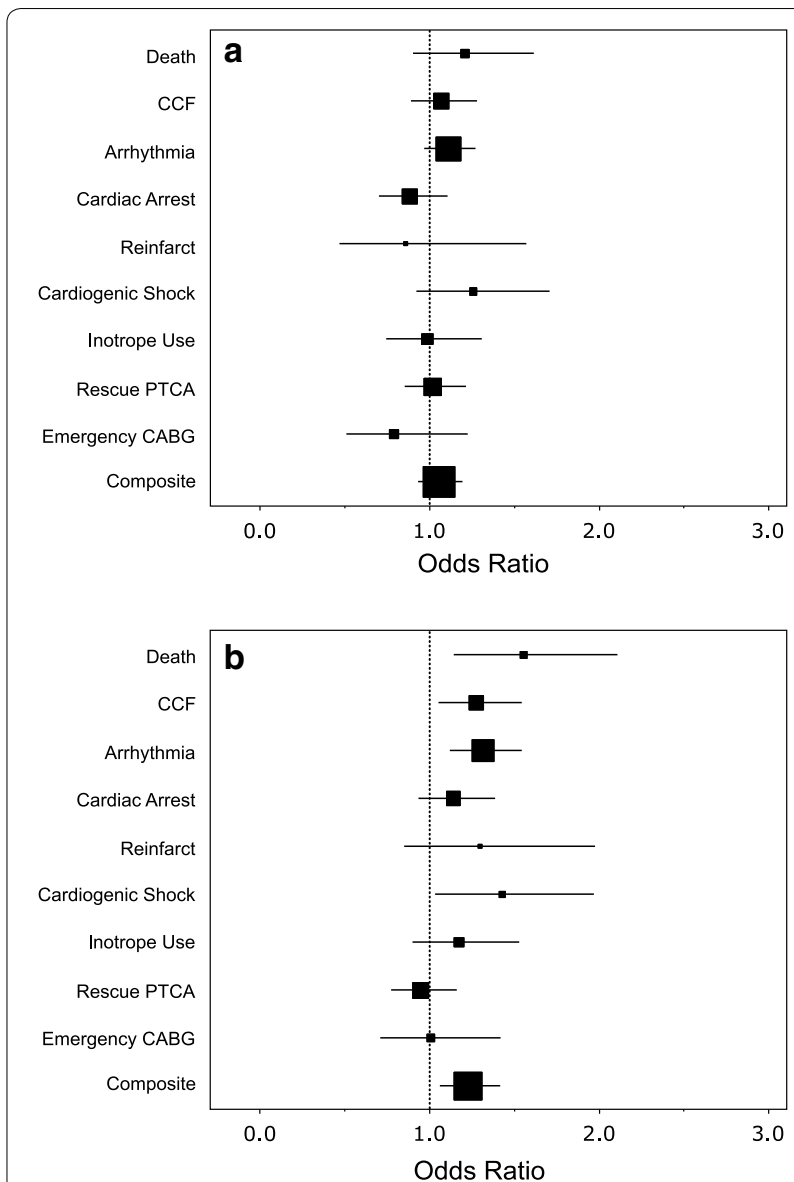

Fig. 1 Odds ratios for the risk of complications of an acute myocardial infarction in 192 patients. a Complications per $1 \mathrm{mmol} / \mathrm{L}$ glucose increment and $\mathbf{b} 0.1$ stress hyperglycemia ratio increment. The size of the squares represent the observed frequency of each complication post myocardial infarction while the whiskers represent the $95 \%$ confidence intervals. CCF $=$ congestive cardiac failure; PTCA $=$ percutaneous transluminal coronary angioplasty; $\mathrm{CABG}=$ coronary arterial bypass graft

significantly modulate the relationship between SHR and a complicated AMI.

\section{Effect of other variables on a complicated acute myocardial infarction}

In univariate analyses, female sex $(\mathrm{p}=0.015)$ and hypoglycemia $(\mathrm{p}=0.015)$ were significantly associated with a greater risk of a complicated AMI (Table 2). Age, Charlson Comorbidity Index, treatment of the AMI, peak creatinine phosphokinase and ST elevation on ECG were not significantly associated with a complicated AMI. In a multiple regression analysis the relationship between SHR and a complicated AMI was independent of sex and hypoglycemia (Table 2). Female sex and hypoglycemia 

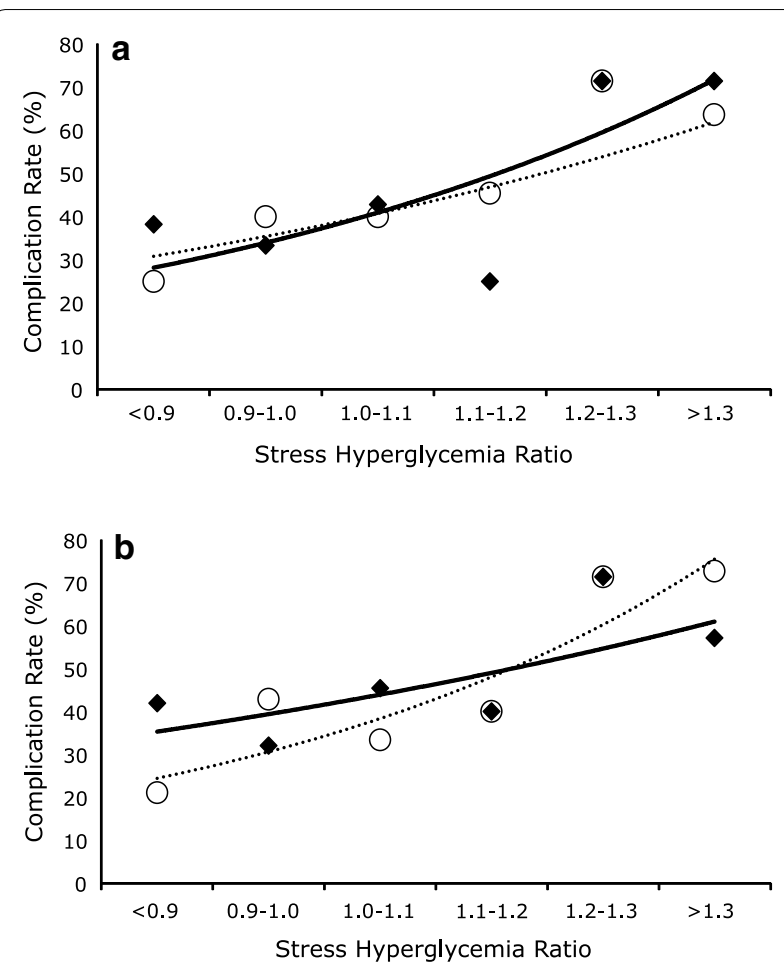

Fig. 2 Rates of a complicated acute myocardial infarction per stress hyperglycemia ratio range in 192 patients. a Patients with (black diamond, solid line) and without (white circle, dotted line) Diabetes Mellitus; and $\mathbf{b}$ patients receiving intensive (black diamond, solid line) or conventional (white circle, dotted line) glucose-lowering therapy

Table 2 Univariate and multivariate analyses of associations between selected variables and a complicated acute myocardial infarction

\begin{tabular}{|c|c|c|c|c|}
\hline \multirow[t]{2}{*}{ Variable } & \multicolumn{2}{|c|}{ Univariate } & \multicolumn{2}{|c|}{ Multivariate } \\
\hline & $\beta$ & $p$ value & $\beta$ & p value \\
\hline Sex & -0.888 & 0.015 & -0.917 & 0.017 \\
\hline Age & 0.021 & 0.108 & NA & \\
\hline SHR & 0.202 & 0.006 & 0.245 & 0.002 \\
\hline Charlson Score ${ }^{a}$ & 1.105 & 0.740 & NA & \\
\hline Hypoglycemia & 1.109 & 0.049 & 1.218 & 0.038 \\
\hline Treatment $^{b}$ & -0.094 & 0.590 & NA & \\
\hline Peak CPKa & -0.382 & 0.169 & NA & \\
\hline STEMI ${ }^{c}$ & 0.102 & 0.779 & & \\
\hline
\end{tabular}

NA not assessed, SHR stress hyperglycemia ratio, Peak CPK peak creatinine phosphokinase, STEMI ST elevation on ECG or presence of Q-waves

a Log transformed for statistical analysis

b Treatment groups were heparin or low-molecular weight heparin, thrombolysis or percutaneous transluminal coronary angioplasty

c There were 6 missing STEMI status which were excluded in this analysis were also independently associated with a complicated myocardial infarction.

\section{Discussion}

Our secondary analysis of the HI-5 study observed no significant association between absolute glycemia during glucose-lowering treatment, defined as the mean finger prick BGL during the first $24 \mathrm{~h}$ post-AMI, and a complicated AMI. In contrast, when mean BGL was corrected for background glycemia to estimate relative glycemia, it was positively associated with a complicated AMI. Moreover, the association with relative glycemia was independent of diabetes status, treatment group and a number of other variables that potentially affect the prognosis after an AMI. As relative glycemia during glucose-lowering treatment is more strongly associated with patient outcomes than absolute glycemia, we hypothesize that defining individualized therapeutic glucose targets based on relative, and not absolute, glycemia could potentially reduce morbidity and mortality after an AMI.

\section{Absolute hyperglycemia and mortality}

A number of studies have reported that glucose concentration on admission to hospital is positively associated with mortality in patients with an AMI [1, 3, 16-19]. Moreover, the association between mortality and mean glucose during hospitalization is even stronger than with admission glucose [16, 20-22]. In contrast, in the HI-5 patient cohort mean glucose concentration during glucose-lowering treatment was not significantly associated with a complicated AMI or any individual component of this composite endpoint. There are a number of potential explanations for this negative result. Firstly, approximately half the patients in the HI-5 study had diabetes and the association between glucose concentration and mortality is attenuated in this group [3, 16, 23]. Secondly, the primary endpoint of this analysis is a composite and there may be individual components of the endpoint that are not related to glucose concentration. Most importantly, the sample size in this analysis is relatively small compared to previous studies.

\section{Relative hyperglycemia and mortality}

Measurement of $\mathrm{HbA}_{1 \mathrm{c}}$ in addition to glucose has revolutionized the management of chronic hyperglycemia, where $\mathrm{HbA}_{1 \mathrm{c}}$ is both a diagnostic test for diabetes and the primary measurement used to guide the need for and efficacy of glucose-lowering therapy [24]. In addition to a clear relationship with microvascular disease, a lower HbA1c during long-term follow-up has been associated 
with reduced macrovascular disease $[25,26]$. It has also been hypothesized that $\mathrm{HbA}_{1 \mathrm{c}}$ could be used to quantify stress or relative hyperglycemia and assist management of acute hyperglycemia [27, 28]. However, other studies have utilized varying definitions of stress hyperglycemia based on absolute glucose concentrations, sometimes taking a patients' diabetic status into account [20, 29, 30]. While it has been proposed that therapeutic targets should differ in patients with and without diabetes, the optimum method to quantify relative glycemia remains to be determined [28, 31]. SHR is a novel metric to quantify relative glycemia in a single numerical value that is cheap to measure and simple to calculate. It directly relates a patient's current glucose control during an acute presentation to their background glycemia, providing an individualized quantification of stress or relative hyperglycemia.

In contrast to absolute glycemia, relative glycemia during glucose-lowering treatment was positively and significantly associated with mortality, heart failure, arrhythmia, cardiogenic shock and a composite endpoint of a complicated AMI in the HI-5 study. These associations between relative glycemia and a number of adverse patient outcomes are striking, given the fairly small sample size in this analysis. Our study extends previous observations by demonstrating that relative hyperglycemia during glucose-lowering treatment is also associated with adverse outcomes in patients with and without diabetes. This suggests that a management strategy that selectively targets glucose-lowering therapy for patients with an elevated SHR irrespective of prior diabetes status may improve outcomes after an AMI.

Others have reported that relative hyperglycemia at admission to hospital has been associated with poor outcomes in patients with acute illness [10], stroke [9], acute myocardial infarction [30,32] and in cardiogenic shock [33]. In addition to SHR two other measures of relative glycemia have been proposed. The "glycemic gap" is the difference between the admission glucose and the estimated average glucose i.e. it is the absolute rather than the relative difference in glucose concentration [11, 32, 34]. Another proposal was for a "glucose concentration-to-HbA1c ratio", in which the admission glucose is divided by the HbA1c [9]. This is theoretically similar to SHR. Whether one measure has advantages over the others has yet to be fully determined, although they are likely perform similarly [9].

\section{Effects of diabetes status and insulin use}

During long-term follow-up of patients with AMI diabetes is associated with increased mortality $[35,36]$. However, during a hospital admission the association between absolute glycemia and mortality is stronger in patients without, as opposed to with, diabetes $[3,6,18]$. We previously reported that the relationship between relative glycemia and critical illness was similar in patients with and without background hyperglycemia [8]. In this analysis, relative glycemia was also associated with a complicated AMI independent of diabetes, which was not independently associated with a complicated AMI (Fig. 2a). This suggests that relative hyperglycemia is clinically important regardless of diabetes status.

A potential confounder in this analysis is that half the cohort was randomized to intensive insulin therapy, which will lower absolute, and consequently relative, glycemia. However, the $0.7 \mathrm{mmol} / \mathrm{L}$ difference in absolute glucose between the two groups was not statistically significant [13]. Furthermore, the positive association between relative glycemia and a complicated AMI was independent of treatment group. Treatment group itself was not independently associated with a complicated AMI and there was not a significant interaction between treatment group and SHR in regression analysis. This suggests that insulin treatment did not confound the relationship between relative glycemia and a complicated AMI.

\section{Other variables affecting outcomes}

The other variables that were independently associated with a complicated AMI were female sex and hypoglycemia. The association between female sex and a poorer outcome after an AMI is consistent with previous studies $[37,38]$. An association between hypoglycemia after an AMI and mortality is well described [16, 19, 39]. However, previous studies have reported that the association is predominantly in patients with spontaneous hypoglycemia while not on insulin therapy and at admission to hospital $[19,39]$. In our study, hypoglycemia during glucose-lowering treatment was independently associated with a complicated AMI. This suggests that if a therapeutic approach targeting relative glycemia were to be trialled, it will be important to avoid hypoglycemia.

Some variables that are usually associated with poor outcomes after AMI were not statistically significant in our analyses. ST elevation was not a predictor of complicated AMI. Our analysis cannot determine the reason for this, but we postulate contributory factors include that only patients with STEMI were revascularized, the primary endpoint was composite and that the sample size was relatively small. The association between age and complicated AMI was positive but did not reach statistical significance $(\mathrm{p}=0.108)$. Peak CK also did not show an association with poorer composite outcomes. Only peak $\mathrm{CK}$ was measured and recorded, as CKMB and troponin 
measurements were not routine at the time of the HI-5 study. Other variables can affect peak $\mathrm{CK}$, such as procedures like PTCA.

\section{Mechanisms linking stress hyperglycemia and patient outcomes}

An elevation in plasma glucose concentration is potentially an epiphenomenon and not directly contributing to cardiovascular events. For example, patients with an AMI have elevations of serum cortisol that could mediate both an increase in blood glucose and contribute to increased cardiovascular risk [40-42]. However, a number of mechanisms have been proposed by which stress hyperglycemia could directly increase morbidity and mortality after an AMI. These include endothelial apoptosis, endothelial dysfunction and oxidative stress [43-46]. Interventional studies demonstrating that lowering plasma glucose reduces cardiovascular events are needed to confirm that stress hyperglycemia per se increases cardiovascular risk.

Studies that have lowered glucose concentration to a target absolute glucose range using insulin therapy have produced conflicting results [13, 47, 48]. Consequently, the importance of this therapeutic approach has not been clearly defined, supported only by a low-level of evidence in clinical practice guidelines $[20,49,50]$. As relative glycemia during glucose-lowering treatment is more strongly associated with adverse outcomes, we propose that SHR could be used to derive individualized glycemic targets for patients with an AMI. If this improved patient outcomes it would represent a paradigm shift in the management of hyperglycemia in hospitalized patients. Treatment of relative hyperglycemia should be the subject of future interventional studies.

\section{Strengths and limitation}

The strengths of this study include the use of a novel metric that quantifies stress hyperglycemia as a continuous variable, a patient population that reflects usual clinical practice, patient data that was systematically and prospectively recorded, and defining a pre-specified primary endpoint before undertaking the analysis. However, we acknowledge that the study has limitations. This is a retrospective, post hoc analysis, and is thus hypothesis generating. The study design cannot show causality, does not assess mechanisms by which relative hyperglycemia could confer a poorer prognosis and does not distinguish whether spontaneous normalization of glucose or insulin treatment underlies a relationship between relative hypoglycemia and a complicated AMI. In particular, it cannot distinguish whether relative hyperglycemia is simply a marker of the severity or duration of an AMI, or directly contributes to poorer outcomes. Moreover, we did not assess the effect of other variables in this analysis that potentially affect cardiovascular outcomes, such as glycemic variability and postprandial hyperglycemia $[51,52]$. Another potential limitation is that glucose was assessed using point of care BGLs, which may differ from gold standard laboratory measurements. However, this approach reflects usual clinical practice. Management of AMI has also changed since the HI-5 study, notably the greater use of PTCA. This could potentially affect results, although treatment was not a predictor of outcome in this analysis. The mortality rate was fairly low in this study and the results may not be able to be extrapolated to patient groups with a higher mortality rate. Finally, the sample size was relatively small, which may have resulted in a type 2 error, especially in subgroup analysis of treatment groups as the numbers of patients in the insulintreated group with a high SHR were low. Nevertheless, the study was of sufficient size to show a significant independent association between relative glycemia and several cardiovascular endpoints.

\section{Conclusion}

Absolute glucose concentration during glucose-lowering treatment following an AMI was not significantly associated with a complicated AMI. In contrast, SHR was positively associated with mortality, heart failure, arrhythmia, cardiogenic shock and a composite endpoint of a complicated AMI. We conclude that relative glycemia during glucose-lowering treatment is more strongly associated with adverse outcomes than absolute glycemia in patients after an AMI. This research adds to other published research by demonstrating the prognostic utility of quantifying relative hyperglycemia during glucose-lowering treatment after an AMI, and should provide a basis for prospective studies using relative, rather than absolute, glycemic thresholds for intervention and therapeutic glycemic targets.

\section{Authors' contributions}

TFL assisted with design of this analysis, performed the statistical analysis and drafted and revised the manuscript; MGB designed this analysis, assisted with the statistical analysis and drafted and revised the manuscript; LKH assisted with manuscript revision; AAM assisted with manuscript revision; VWW assisted with design of the $\mathrm{HI}-5$ study, subject recruitment and manuscript revision; MM assisted with design of the HI-5 study, subject recruitment and manuscript revision; NWC designed the HI-5 study and assisted with subject recruitment and manuscript revision. All authors read and approved the final manuscript.

\section{Authors' information}

Prof Cheung is a former President of the Australian Diabetes Society, and has a research interest in the care of people with hyperglycemia in hospital. He has conducted trials of glucose control in myocardial infarction and stroke, and led the development of guidelines for management of hyperglycemia in hospital in Australia. The HI-5 Study is one of a limited number of clinical trials which have focused on glucose control to improve outcomes of myocardial infarction. 


\begin{abstract}
Author details
${ }^{1}$ School of Medicine, Flinders University, Adelaide, Australia. ${ }^{2}$ Southern Adelaide Diabetes \& Endocrine Services, Repatriation General Hospital, Daw Park, Adelaide, SA 5041, Australia. ${ }^{3}$ The University of Adelaide, Adelaide, Australia. ${ }^{4}$ Centre for Diabetes \& Endocrinology Research, Westmead Hospital, Sydney, Australia.
\end{abstract}

\section{Acknowledgements}

Not applicable.

\section{Competing interests}

The authors declare that they have no competing interests.

\section{Availability of data and materials}

The data that support the findings of this study are available from the $\mathrm{HI}-5$ group of researchers but restrictions apply to the availability of these data, which were used under license for the current study, and so are not publicly available. Data are however available from the authors upon reasonable request and with permission of the original authors of the HI-5 study.

\section{Consent for publication}

Not applicable.

\section{Ethics approval and consent to participate}

The study was approved by local ethics committees of Westmead Hospital, Nepean Hospital, Blacktown Hospital, Mt. Druitt Hospital and John Hunter Hospital. All subjects participating in the study provided written informed consent.

\section{Funding}

The HI-5 study was supported by a project grant from the National Health and Medical Research Council, Australia. Novo Nordisk sponsored a dinner meeting for the HI-5 study. TL is supported by a scholarship from the National Health and Medical Research Council, Australia and the Royal Australasian College of Physicians Kincaid-Smith scholarship.

\section{Publisher's Note}

Springer Nature remains neutral with regard to jurisdictional claims in published maps and institutional affiliations.

Received: 3 August 2017 Accepted: 6 December 2017 Published online: 12 December 2017

\section{References}

1. Baker EH, Janaway CH, Philips BJ, Brennan AL, Baines DL, Wood DM, et al. Hyperglycaemia is associated with poor outcomes in patients admitted to hospital with acute exacerbations of chronic obstructive pulmonary disease. Thorax. 2006;61:284-9.

2. Capes SE, Hunt D, Malmberg K, Pathak P, Gerstein HC. Stress hyperglycemia and prognosis of stroke in nondiabetic and diabetic patients: a systematic overview. Stroke. 2001;32:2426-32.

3. Capes SE, Hunt D, Malmberg K, Gerstein HC. Stress hyperglycaemia and increased risk of death after myocardial infarction in patients with and without diabetes: a systematic overview. Lancet. 2000;355:773-8.

4. Umpierrez GE, Isaacs SD, Bazargan N, You X, Thaler LM, Kitabchi AE. Hyperglycemia: an independent marker of in-hospital mortality in patients with undiagnosed diabetes. J Clin Endocrinol Metab. 2002;87:978-82.

5. Lanspa MJ, Hirshberg EL, Phillips GD, Holmen J, Stoddard G, Orme J. Moderate glucose control is associated with increased mortality compared with tight glucose control in critically ill patients without diabetes. Chest. 2013;143:1226-34.

6. Kim EJ, Jeong MH, Kim JH, Ahn TH, Seung KB, Oh DJ, et al. Clinical impact of admission hyperglycemia on in-hospital mortality in acute myocardial infarction patients. Int J Cardiol. 2017;236:9-15.

7. Dungan KM, Braithwaite SS, Preiser J-C. Stress hyperglycaemia. Lancet. 2009;373:1798-807.
8. Roberts GW, Quinn SJ, Valentine N, Alhawassi T, O'Dea H, Stranks SN, et al. Relative hyperglycemia, a marker of critical illness: introducing the stress hyperglycemia ratio. J Clin Endocrinol Metab. 2015;100:4490-7.

9. Yang C-J, Liao W-I, Wang J-C, Tsai C-L, Lee J-T, Peng G-S, et al. Usefulness of glycated hemoglobin A1c-based adjusted glycemic variables in diabetic patients presenting with acute ischemic stroke. Am J Emerg Med. 2017;35:1240-6.

10. Su Y-W, Hsu C-Y, Guo Y-W, Chen H-S. Usefulness of the plasma glucose concentration-to-HbA1c ratio in predicting clinical outcomes during acute illness with extreme hyperglycaemia. Diabetes Metab. 2017:43:40-7

11. Liao W, Wang J, Chang W, Hsu C, Chu C-M, Tsai S-H. Usefulness of glycemic gap to predict ICU mortality in critically ill patients with diabetes. Medicine (Baltimore). 2015;94:e1525.

12. Yang Y, Kim T-H, Yoon K-H, Chung WS, Ahn Y, Jeong M-H, et al. The stress hyperglycemia ratio, an index of relative hyperglycemia, as a predictor of clinical outcomes after percutaneous coronary intervention. Int J Cardiol. 2017;241:57-63.

13. Cheung NW, Wong VW, McLean M. The Hyperglycemia: intensive insulin infusion in infarction (HI-5) study: a randomized controlled trial of insulin infusion therapy for myocardial infarction. Diabetes Care. 2006;29:765-70.

14. Charlson ME, Pompei P, Ales KL, Mackenzie CR. A new method of classifying prognostic comorbidity in longitudinal studies: development and validation. J Chronic Dis. 1987;40:373-83.

15. Nathan DM, Kuenen J, Borg R, Zheng H, Schoenfeld D, Heine RJ. Translating the $\mathrm{A} 1 \mathrm{C}$ assay into estimated average glucose values. Diabetes Care. 2008;31:1473-8.

16. Kosiborod M, Inzucchi SE, Krumholz HM, Xiao L, Jones PG, Fiske S, et al. Glucometrics in patients hospitalized with acute myocardial infarction: defining the optimal outcomes-based measure of risk. Circulation. 2008;117:1018-27.

17. Wernly B, Lichtenauer M, Franz M, Kabisch B, Muessig J, Masyuk M, et al. Differential impact of hyperglycemia in critically ill patients: significance in acute myocardial infarction but not in sepsis? Int J Mol Sci. 2016;17(9):1586.

18. Kosiborod M, Rathore SS, Inzucchi SE, Masoudi FA, Wang Y, Havranek EP, et al. Admission glucose and mortality in elderly patients hospitalized with acute myocardial infarction: implications for patients with and without recognized diabetes. Circulation. 2005;111:3078-86.

19. Goyal A, Mehta SR, Díaz R, Gerstein HC, Afzal R, Xavier D, et al. Differential clinical outcomes associated with hypoglycemia and hyperglycemia in acute myocardial infarction. Circulation. 2009;120:2429-37.

20. Deedwania P, Kosiborod M, Barrett E, Ceriello A, Isley W, Mazzone T, et al. Hyperglycemia and acute coronary syndrome: a scientific statement from the American Heart Association Diabetes Committee of the Council on Nutrition, Physical Activity, and Metabolism. Circulation. 2008;117:1610-9.

21. Suleiman M, Hammerman H, Boulos M, Kapeliovich MR, Suleiman A, Agmon $Y$, et al. Fasting glucose is an important independent risk factor for 30-day mortality in patients with acute myocardial infarction: a prospective study. Circulation. 2005;111:754-60.

22. Goyal A, Mahaffey KW, Garg J, Nicolau JC, Hochman JS, Weaver WD, et al. Prognostic significance of the change in glucose level in the first $24 \mathrm{~h}$ after acute myocardial infarction: results from the CARDINAL study. Eur Heart J. 2006;27:1289-97.

23. Umpierrez G, Cardona S, Pasquel F, Jacobs S, Peng L, Unigwe M, et al. Randomized controlled trial of intensive versus conservative glucose control in patients undergoing coronary artery bypass graft surgery: GLUCO-CABG trial. Diabetes Care. 2015;38:1665-72.

24. Chamberlain JJ, Rhinehart AS, Shaefer CF, Neuman A. Diagnosis and management of diabetes: synopsis of the 2016 American Diabetes Association Standards of Medical Care in Diabetes. Ann Intern Med. 2016;164:542-52

25. Wang P, Huang R, Lu S, Xia W, Sun H, Sun J, et al. HbA1c below $7 \%$ as the goal of glucose control fails to maximize the cardiovascular benefits: a meta-analysis. Cardiovasc Diabetol. 2015;14:124.

26. Bots SH, van der Graaf Y, Nathoe HMW, de Borst GJ, Kappelle JL, Visseren $\mathrm{FLJ}$, et al. The influence of baseline risk on the relation between $\mathrm{HbA} 1 \mathrm{C}$ and risk for new cardiovascular events and mortality in patients with type 2 diabetes and symptomatic cardiovascular disease. Cardiovasc Diabetol. 2016:15:101. 
27. Braithwaite SS. Through the eyes of the A1C: a call to re-examine stress hyperglycemia. Crit Care Med. 2010;38:717-9.

28. Marik PE, Egi M. Treatment thresholds for hyperglycemia in critically ill patients with and without diabetes. Intensive Care Med. 2014:40:1049-51.

29. Koracevic GP, Petrovic S, Damjanovic M, Stanojlovic T. Association of stress hyperglycemia and atrial fibrillation in myocardial infarction. Wien Klin Wochenschr. 2008;120:409-13.

30. Fujino M, Ishihara M, Honda S, Kawakami S, Yamane T, Nagai T, et al. Impact of acute and chronic hyperglycemia on in-hospital outcomes of patients with acute myocardial infarction. Am J Cardiol. 2014;114:1789-93.

31. Koracevic GP. Proposal of a new approach to study and categorize stress hyperglycemia in acute myocardial infarction. J Emerg Med. 2016;51:31-6.

32. Liao W-I, Lin C-S, Lee C-H, Wu Y-C, Chang W-C, Hsu C-W, et al. An elevated glycemic gap is associated with adverse outcomes in diabetic patients with acute myocardial infarction. Sci Rep. 2016:6:27770.

33. Kataja A, Tarvasmäki T, Lassus J, Cardoso J, Mebazaa A, Køber L, et al. The association of admission blood glucose level with the clinical picture and prognosis in cardiogenic shock - results from the CardShock Study. Int J Cardiol. 2017:226:48-52.

34. Liao W-I, Sheu W-H, Chang W-C, Hsu C-W, Chen Y-L, Tsai S-H. An elevated gap between admission and A1C-derived average glucose levels is associated with adverse outcomes in diabetic patients with pyogenic liver abscess. PLoS ONE. 2013;8(5):e64476.

35. Kuhl J, Jörneskog G, Wemminger M, Bengtsson M, Lundman P, Kalani M. Long-term clinical outcome in patients with acute coronary syndrome and dysglycaemia. Cardiovasc Diabetol. 2015;14:120.

36. Pararajasingam G, Høfsten DE, Løgstrup BB, Egstrup M, Henriksen FL, Hangaard J, et al. Newly detected abnormal glucose regulation and longterm prognosis after acute myocardial infarction: comparison of an oral glucose tolerance test and glycosylated haemoglobin A1c. Int J Cardiol. 2016;214:310-5

37. Maas AHEM, Appelman YEA. Gender differences in coronary heart disease. Neth Heart J. 2010;18:598-602.

38. Hochman JS, Tamis JE, Thompson TD, Weaver WD, White HD, Van de Werf F, et al. Sex, clinical presentation, and outcome in patients with acute coronary syndromes. global use of strategies to open occluded coronary arteries in acute coronary syndromes Ilb investigators. N Engl J Med. 1999;341:226-32.

39. Kosiborod M, Inzucchi SE, Goyal A, Krumholz HM, Masoudi FA, Xiao L, et al. Relationship between spontaneous and iatrogenic hypoglycemia and mortality in patients hospitalized with acute myocardial infarction. JAMA. 2009;301:1556-64.

40. Carmen Wong KY, Wong V, Ho JT, Torpy DJ, McLean M, Cheung NW. High cortisol levels in hyperglycaemic myocardial infarct patients signify stress hyperglycaemia and predict subsequent normalization of glucose tolerance. Clin Endocrinol (Oxf). 2010;72:189-95.
41. Petersons CJ, Mangelsdorf BL, Thompson CH, Burt MG. Acute effect of increasing glucocorticoid replacement dose on cardiovascular risk and insulin sensitivity in patients with adrenocorticotrophin deficiency. J Clin Endocrinol Metab. 2014;99:2269-76.

42. Petersons CJ, Mangelsdorf BL, Jenkins AB, Poljak A, Smith MD, Greenfield $J R$, et al. Effects of low-dose prednisolone on hepatic and peripheral insulin sensitivity, insulin secretion, and abdominal adiposity in patients with inflammatory rheumatologic disease. Diabetes Care. 2013;36:2822-9.

43. Quagliaro L, Piconi L, Assaloni R, Martinelli L, Motz E, Ceriello A. Intermittent high glucose enhances apoptosis related to oxidative stress in human umbilical vein endothelial cells: the role of protein kinase $C$ and NAD(P)H-oxidase activation. Diabetes. 2003;52:2795-804.

44. Monnier L, Mas E, Ginet C, Michel F, Villon L, Cristol J-P, et al. Activation of oxidative stress by acute glucose fluctuations compared with sustained chronic hyperglycemia in patients with type 2 diabetes. JAMA. 2006:295:1681-7.

45. Ceriello A, Esposito K, Piconi L, Ihnat MA, Thorpe JE, Testa R, et al. Oscillating glucose is more deleterious to endothelial function and oxidative stress than mean glucose in normal and type 2 diabetic patients. Diabetes. 2008:57:1349-54

46. Evans JL, Goldfine ID, Maddux BA, Grodsky GM. Oxidative stress and stress-activated signaling pathways: a unifying hypothesis of type 2 diabetes. Endocr Rev. 2002;23:599-622.

47. Malmberg K. Prospective randomised study of intensive insulin treatment on long term survival after acute myocardial infarction in patients with diabetes mellitus. DIGAMI (Diabetes Mellitus, Insulin Glucose Infusion in Acute Myocardial Infarction) Study Group. BMJ. 1997;314:1512-5.

48. Malmberg K, Rydén L, Wedel H, Birkeland K, Bootsma A, Dickstein K, et al. Intense metabolic control by means of insulin in patients with diabetes mellitus and acute myocardial infarction (DIGAMI 2): effects on mortality and morbidity. Eur Heart J. 2005;26:650-61.

49. Jacobi J. Liberal glucose targets for critically ill diabetic patients: is it time for large clinical trials with more personalized endpoints? Ann Transl Med. 2016;4:358.

50. Umpierrez GE, Hellman R, Korytkowski MT, Kosiborod M, Maynard GA, Montori VM, et al. Management of hyperglycemia in hospitalized patients in non-critical care setting: an endocrine society clinical practice guideline. J Clin Endocrinol Metab. 2012;97:16-38.

51. Strojek K, Raz I, Jermendy G, Gitt AK, Liu R, Zhang Q, et al. Factors associated with cardiovascular events in patients with type 2 diabetes and acute myocardial infarction. J Clin Endocrinol Metab. 2016;101:243-53.

52. Okada K, Hibi K, Gohbara M, Kataoka S, Takano K, Akiyama E, et al. Association between blood glucose variability and coronary plaque instability in patients with acute coronary syndromes. Cardiovasc Diabetol. 2015;14:111.

\section{Submit your next manuscript to BioMed Central and we will help you at every step:}

- We accept pre-submission inquiries

- Our selector tool helps you to find the most relevant journal

- We provide round the clock customer support

- Convenient online submission

- Thorough peer review

- Inclusion in PubMed and all major indexing services

- Maximum visibility for your research

Submit your manuscript at www.biomedcentral com/submit
BioMed Central 